\title{
Designing a Branding Model for Public Teaching Hospitals in Iran
}

\author{
Elham Afzal ${ }^{1}$, Mohammad Hossein Modarresi ${ }^{*}$, Mohammad Reza Maleki ${ }^{3}$, \\ Amir Ashkan Nasiripour ${ }^{1}$ \\ ${ }^{1}$ Department of Health Services Administration, Science and Research Branch, Islamic Azad University, Tehran, \\ Iran. ${ }^{2}$ Department of Biology, Science and Research Branch, Islamic Azad University, Tehran, Iran. ${ }^{3}$ School of \\ Management and Medical Information Services, Iran University of Medical Sciences, Tehran, Iran.
}

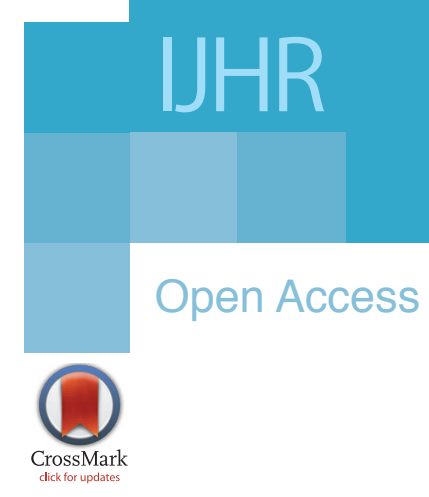

First Published online June 30, 2016

\begin{abstract}
Background and Objectives: Hospital branding is a new concept in Iran that requires focused attention in order to enhance economic performance of health care delivery system. This study aimed to develop a conceptual framework for initiation and promotion of public teaching hospital brand in an Iranian context.

Methods: A comparative study of hospital branding in 8 pioneer countries revealed 51 elements potentially influencing successful hospital branding. Based on expert opinion, these elements were refined and adapted to the Iranian context. Based on this information a 47-item questionnaire was designed. The questionnaire was distributed among 364 experts from different health domains, including clinicians of public and private hospitals and policy makers, executives, and authorized advisors from the Ministry of Health and Medical Education (MOHME) and various medical universities. The collected data were analyzed using exploratory factors analysis in order to identify factors influencing hospital branding. The robustness of the identified factors was further explored by confirmatory factor analysis (CFA).
\end{abstract}

Findings: Identity, image, competitiveness, strategy, and relationship were identified as the five key dimensions of hospital branding in the Iranian context.

Conclusions: Identification of the major dimensions of hospital branding may help policy-makers to develop effective brand promotion strategies in hospital industry.

Keywords: Hospital, Branding, Healthcare, Marketing

\section{Background and Objectives}

Hospitals constitute the most important components of the health systems, given their role in direct delivery of health care services as well as being the major consumer of health budget and resources. ${ }^{1}$ Nonetheless, along with the rapid global transformation of societies, increasing costs of patient care, advancement of medical technologies, increasing demand for quality health care, competitive pressures, and promotion of non-centralized care, constantly challenge hospitals' capability to maintain economic viability together with quality of care. ${ }^{2}$

In order to overcome these challenges public hospitals need to revise the way they provide services and reorder their services delivery structure to adjust the continuous changes. ${ }^{3}$ One of the commercial tool for promoting eco-

${ }^{*}$ Corresponding Author: Mohammad Hossein Modarresi, Department of Biology, Science and Research Branch, Islamic Azad University, Tehran, Iran. Tel: +98 2144865239 , Email: modaresi@tums.ac.ir nomic viability and competiveness of firms is branding. Brand is a non-tangible asset of an enterprise bringing lots of advantages if utilized effectively. ${ }^{4}$ Although branding is a new concept in the Iranian health system, studies show that appropriate hospital branding can enhance the hospital economy, improve patients' confidence, and loyalty, and thereby strength the foundation of health system. .,6 These advantages are exactly what the health system needs. Professional branding will inform patients on the comparative advantages health care processes and services in provided by a particular hospital and induce higher levels of trust and confidence. ${ }^{7}$

Hospital branding has not been systematically dealt with in the Iranian context. Lack of academic literature as well as managerial experience in this area, contributes to limited attention of the health care policy-makers and managers to the importance of issue. To help fill this gap, the present study was designed aiming at developing a 
conceptual model for successful promotion of hospital branding.

\section{Methods}

A comparative study of hospital branding strategies in 8 pioneer countries, including Britain, Canada, Australia, New Zealand, China, Ireland, South Korea and South Africa was carried out using content analysis method. As a result, 51 elements potentially influencing successful hospital branding were identified, which were used to design an assessment model. The validity of the assessment model was sought by expert opinion method (10 experts). As a result, 2 items were excluded, 3 new items were added, and some other items were revised based on the experts' recommendations. The resulting model comprised 52 items, scored on a 5-point Likert-type scale (from 1 = "very week" to 5 = "very strong"). The reliability of the questionnaire was ensured by Cronbach $\alpha$ of .64 .

The questionnaire was distributed among a sample of 364 individuals purposefully selected from among medical board members, health policy-makers, medical university professors, the Ministry of Health and Medical Education (MOHME) officials, and hospital administrators.

Exploratory factor analysis (EFA) was used to identify the factor structures underlying the data. Kaiser-Meyer-Olkin (KMO) of 0.73 ensured the sufficiency of sample size for factor analysis. Bartlett's test of sphericity showed the significance of the correlation matrix. Levene test showed that distribution of variances was homogeneous $(P>$.05). Factors were extracted by principal component analysis with varimax rotation. The internal consistency reliability of the extracted factors was calculated using Cronbach $\alpha$.

The validity of the obtained model was then explored by confirmatory factor analysis (CFA). A series of goodness-of-fit indices including comparative fit index (CFI), goodness-of-fit index (GFI), adjusted goodness-of-fit index (TLI), and root mean squared error of approximation (RMSEA) were calculated to evaluate the extent to which the model represents the structure of the data.

\section{Ethical Issues}

All respondents were informed about the objectives of the study and their verbal consent for participation in the survey was obtained. In addition, the participants were assured of the confidentially of their responses.

\section{Findings}

\section{Literature Review}

Table 1 summarizes the successful strategies in hospital branding adopted by the pioneer countries together with
Iran. Some of these strategies include international cooperation as followed by South Korean hospitals, ${ }^{8}$ release of detailed financial audits and annual reports which was pursued by Alberta Children's Hospital in Canada, ${ }^{9}$ and patient follow-up activities initiated by Hasheminejad Kidney Center in Iran. ${ }^{10}$

\section{Explanatory Factor Analysis and Model Improvement}

Among different EFA solutions with various number of factors, the 5-factor solution yielded the most consistent results. Given the low internal consistency of some extracted factors, the model has to be refined. To obtain a more reliable model, an iterative cycle of model modification was carried out and at each iteration a single item with insufficient factor loading and communality was excluded. The procedure was stopped when all factor loadings reached above than 0.3. This criterion was met after eliminating 5 items. Table 2 shows the specific value, variance, and the cumulative variance of five factors. The specific values of all factors are higher than one. The extracted factors together explain 64.6 of the total variance of the variables. In addition, the internal consistency reliability of the 47item assessment tool was obtained 0.72 . Also all factors in the in the improved model showed adequate internal consistency $(\alpha>.7)$.

Considering the content of factors, they were termed as the following: Factor 1: Identity, Factor 2: Image, Factor 3: Competitiveness, Factor 4: Strategy, Factor 5: Relationships. Table 3 presents the items associated with each factor and the corresponding loading.

We examined the validity of the model by CFA. Results of fitness data analysis (Table 4) shows the appropriate fitness of the assessment model to the data which. This indicates that the five-factor model developed can represent the conceptual structure hospital branding in Iran.

\section{Discussion}

Among subfactors of brand identity, "provision of information about vision, mission, and values of the hospital" gained the highest loading. This observation is confirmed by the results from the study by Kamarposhti, ${ }^{11}$ suggesting that brands are the result of mission, visions, and values of an organization. Alserhan and Alserhan also conclude that brand lays the foundation for reuse of services through creating a sense of dependence and closeness in the customers. ${ }^{12}$

Among subfactors of brand image, "provision of information about the events and new services" received the highest loading. This observation is consistent with the study of Mirabi et $a l,{ }^{13}$ who identified promotion of the brand image as an essential deriver of customers' behavioral inten- 


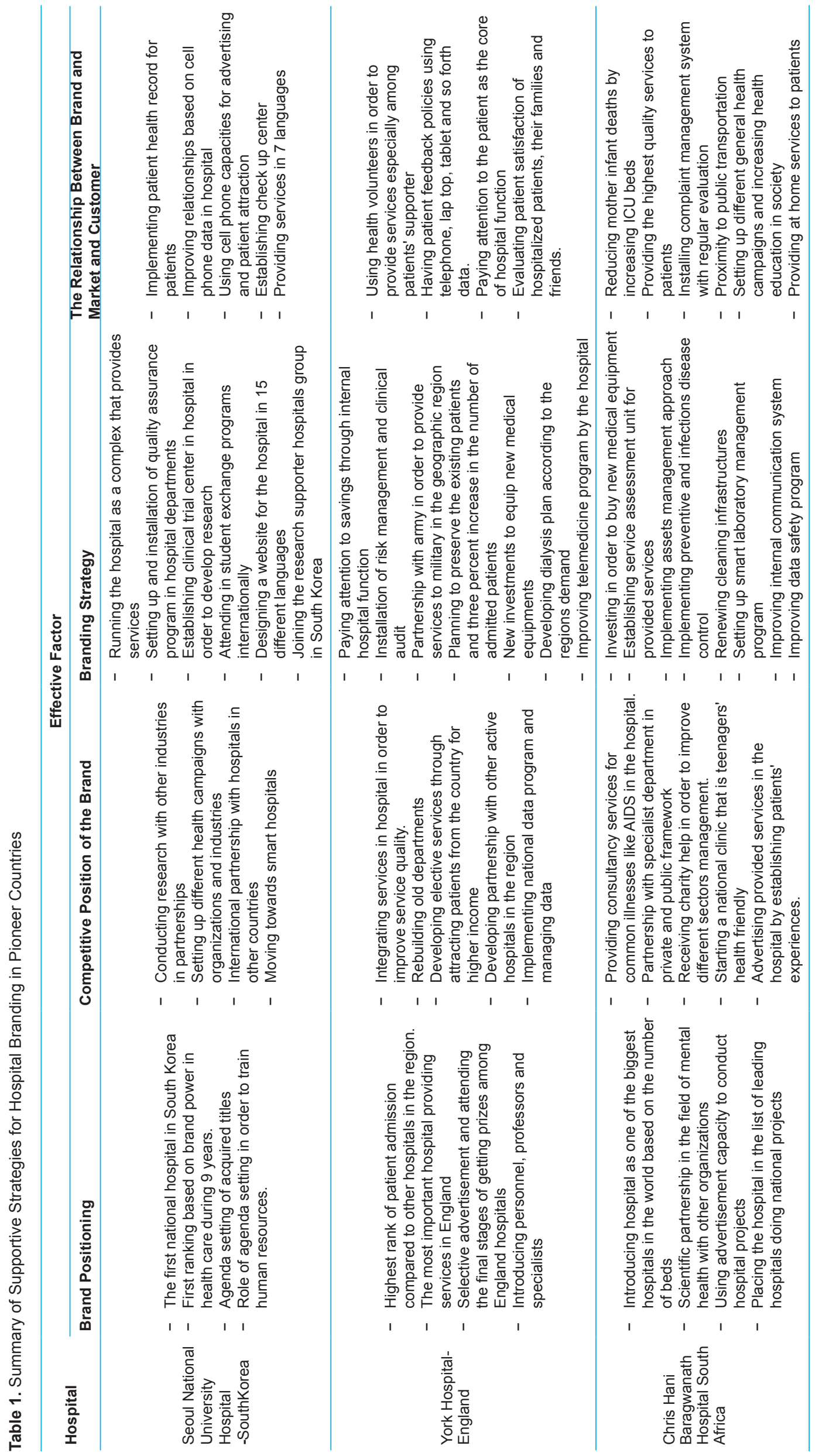




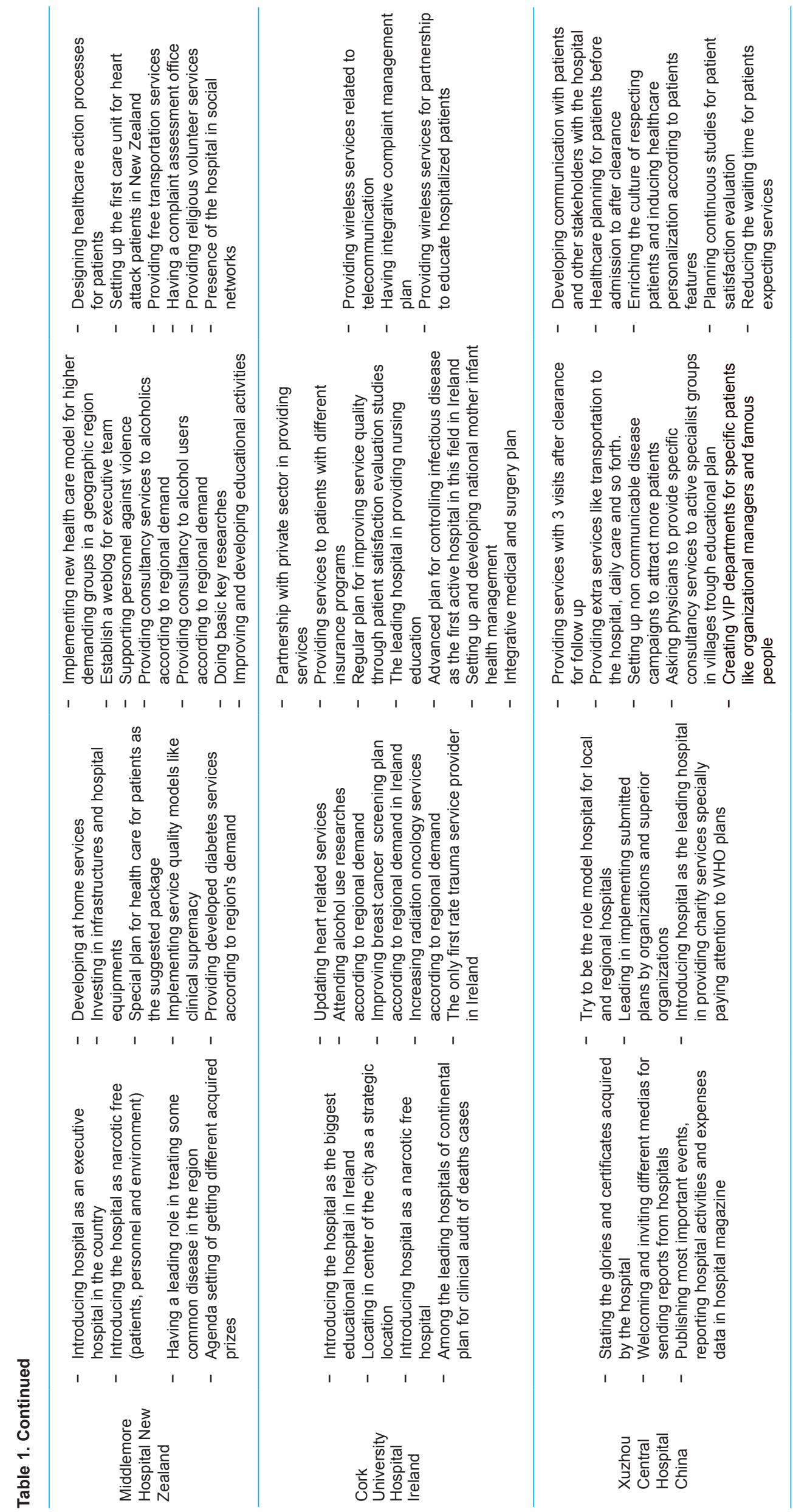




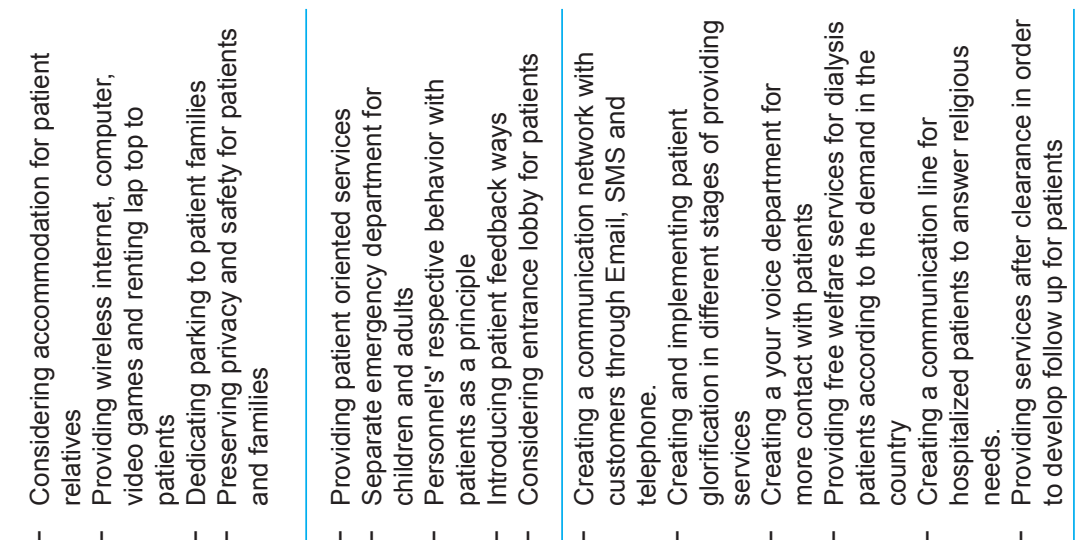

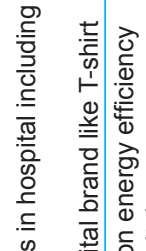

ब

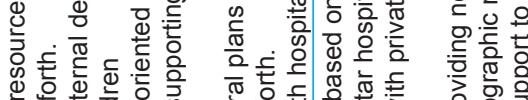

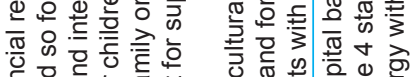

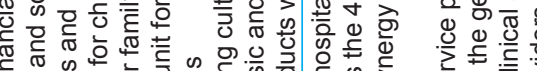

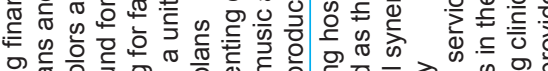

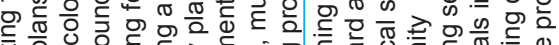

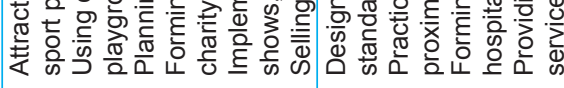

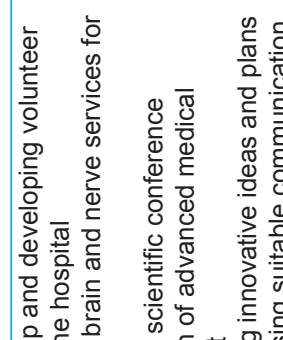

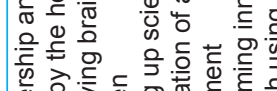
娄

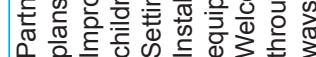

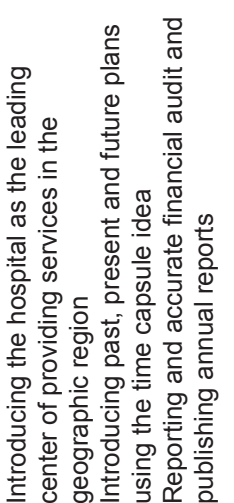

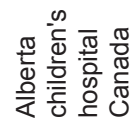
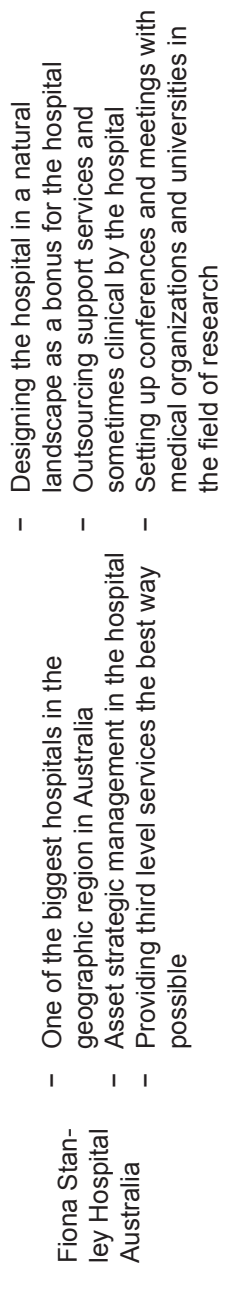

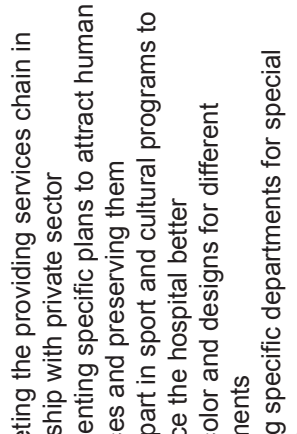

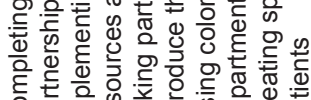

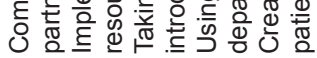
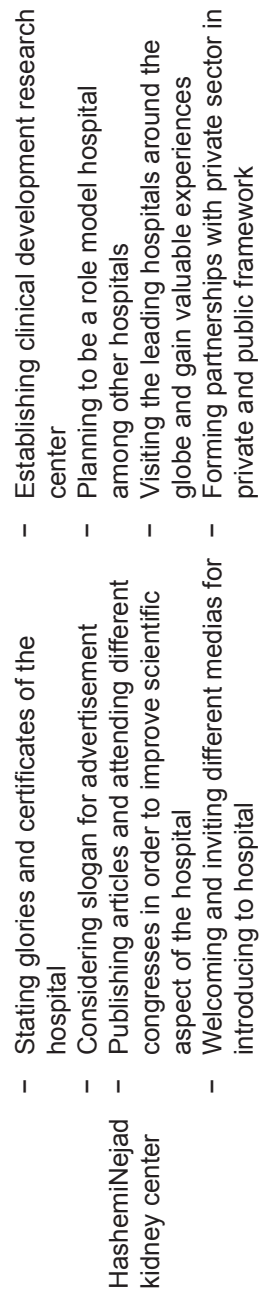

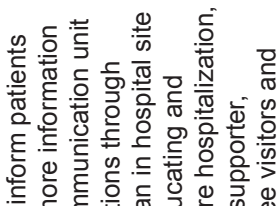

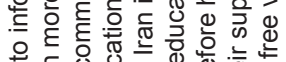

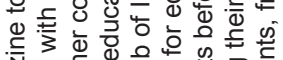

菏 $\frac{E}{0}$ 응

ه

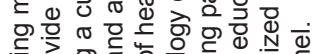

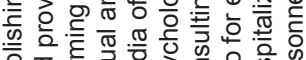

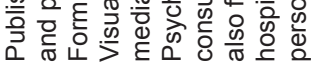

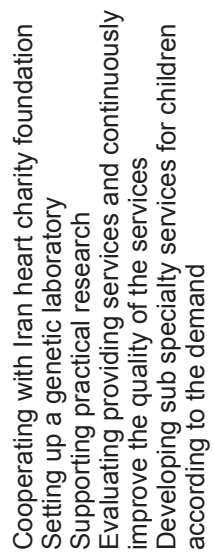

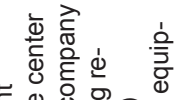

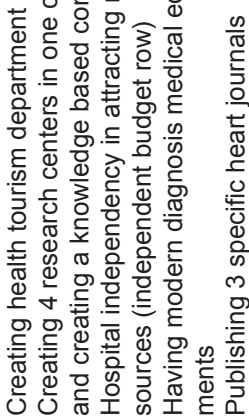
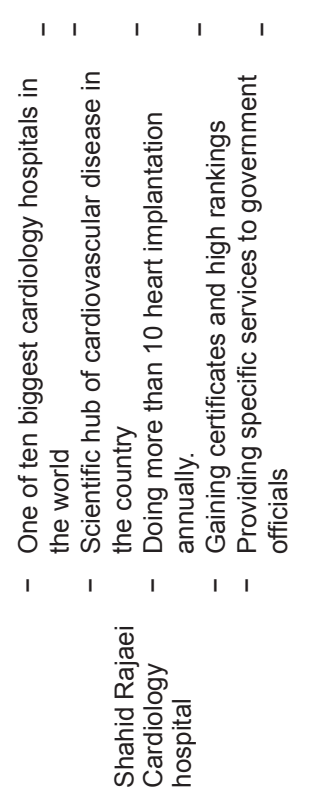
Table 2. Specific Value, Variance Percentage, and the Cumulative Variance Percentage of the Identified Factors

\begin{tabular}{lccc}
\hline Factor & $\begin{array}{c}\text { Specific } \\
\text { Value }\end{array}$ & $\begin{array}{c}\text { Variance } \\
\text { Percentage }\end{array}$ & $\begin{array}{c}\text { 5-Factor Cumulative } \\
\text { Variance (\%) }\end{array}$ \\
\hline Relationship & 5.2 & 16.34 & 16.34 \\
Competitiveness & 3.79 & 17.22 & 33.56 \\
Image & 4.26 & 14.53 & 48.09 \\
Strategy & 2.36 & 8.55 & 56.64 \\
Identity & 2.75 & 7.93 & 64.57 \\
\hline
\end{tabular}

tion. Constantly informing customers on new services and products can promote brand image and increase the credit and value of new services. ${ }^{14}$

Among subfactors of brand competitiveness, "reducing the waiting time for receiving services" represented the highest factor loading. Focus on this concept has produced desirable results in the Yuzhu Hospital of China. ${ }^{15}$ Consistently, the study of Yasin et al also highlights the

Table 3. Factor Loadings From Exploratory and Confirmatory Analysis

\begin{tabular}{|c|c|c|c|}
\hline Main Factors & Factors & $\begin{array}{c}\text { Exploratory } \\
\text { Loading } \\
\text { Factor }\end{array}$ & $\begin{array}{l}\text { Confirmatory } \\
\text { Loading Factor }\end{array}$ \\
\hline \multirow{3}{*}{ Identity } & Choosing an attractive name & 0.71 & 0.19 \\
\hline & Designing an appropriate logo & 0.91 & 0.38 \\
\hline & Informing the vision, mission and values of the hospital & 0.98 & 0.44 \\
\hline \multirow{8}{*}{ Image } & Introducing accomplishments of the hospital & 0.81 & 0.35 \\
\hline & Introducing modern medical equipment and related services & 0.55 & 0.39 \\
\hline & Introducing hospital honors and awards & 0.51 & 0.49 \\
\hline & Providing financial information & 0.45 & 0.48 \\
\hline & Introducing events and new services & 0.96 & 0.41 \\
\hline & $\begin{array}{l}\text { Introducing the important hospital performance indices (like the number of } \\
\text { beds, number of admission, hospital infections, patient satisfaction rate) }\end{array}$ & 0.54 & 0.31 \\
\hline & Introducing human resources skills & 0.43 & 0.16 \\
\hline & Training and empowering the employees & 0.36 & 0.28 \\
\hline \multirow{9}{*}{ Competitiveness } & Professional designing of the hospital & 0.56 & 0.17 \\
\hline & Updating professional services & 0.60 & 0.30 \\
\hline & Employing well known specialists & 0.67 & 0.56 \\
\hline & Advertising the hospital services & 0.60 & 0.27 \\
\hline & Setting a slogan for the hospital & 0.53 & 0.48 \\
\hline & Innovation in services delivery & 0.53 & 0.16 \\
\hline & Reducing patient waiting time & 0.90 & 0.35 \\
\hline & Using the modern equipment & 0.88 & 0.26 \\
\hline & Implementing continuous quality improvement plan & 0.48 & 0.45 \\
\hline \multirow{13}{*}{ Strategy } & Planning to treat patients before admission & 0.84 & 0.15 \\
\hline & Avoiding development of services out of the hospital brand & 0.64 & 0.11 \\
\hline & Setting well-known individuals for managing position & 0.94 & 0.09 \\
\hline & Partnership with private sector & 0.63 & 0.30 \\
\hline & Improving partnership with other public and private hospitals & 0.71 & 0.31 \\
\hline & $\begin{array}{l}\text { Providing information about the specialty of the practitioners working in the } \\
\text { hospital }\end{array}$ & 0.46 & 0.44 \\
\hline & Participating in charity programs & 0.78 & 0.45 \\
\hline & Developing research projects for hospital performance improvement & 0.74 & 0.38 \\
\hline & Providing appropriate training for patients & 0.54 & 0.47 \\
\hline & Redesigning service delivery processes & 0.51 & 0.32 \\
\hline & Providing sideline services such as transportation and home care & 0.38 & 0.38 \\
\hline & $\begin{array}{l}\text { Completing the diagnosis, treatment, and care chain based on the expertize } \\
\text { in the hospital }\end{array}$ & 0.92 & 0.23 \\
\hline & Communication with media & 0.52 & 0.26 \\
\hline \multirow{12}{*}{ Relationship } & Presence in social networks & 0.59 & 0.12 \\
\hline & Appropriate addressing through implementation of signs in the city streets & 0.56 & 0.45 \\
\hline & Providing patient-centered services & 0.37 & 0.32 \\
\hline & Launching patient relationship office & 0.92 & 0.22 \\
\hline & Assessing the satisfaction of patients and their families & 0.42 & 0.47 \\
\hline & Using telecommunication technologies to advertise & 0.42 & 0.44 \\
\hline & Enabling visit time setting by telephone or internet & 0.82 & 0.19 \\
\hline & Launching an active website & 0.42 & 0.35 \\
\hline & Emphasizing the social responsibilities of the hospital & 0.44 & 0.27 \\
\hline & Protecting the privacy and security for patients and their families & 0.49 & 0.49 \\
\hline & Specifying parking for patients' families & 0.47 & 0.54 \\
\hline & Direct communication of hospital managers with the patients & 0.38 & 0.29 \\
\hline
\end{tabular}


Table 4. Goodness-of-Fit Indices Determined From Confirmatory Factor Analysis

\begin{tabular}{ccccccc}
\hline CFI & AGFI & GFI & RMSEA & $\boldsymbol{P}$ & $\boldsymbol{d f}$ & $\chi^{2}$ \\
\hline 0.799 & 0.732 & 0.842 & 0.022 & .001 & 398 & 5604.963 \\
\hline
\end{tabular}

importance of attention to competitiveness in creating opportunity for brand promotion. ${ }^{16}$

Among subfactors branding strategy, "partnerships with other public and private hospitals" received the highest loading. This observation is in line with previous studies emphasizing the importance of co-branding and brand alliances to promotion and establishment of a commercial brand..$^{17,18}$

Among subfactors of relationship, "creating a unit for relationship with customers (addressing patients' problems and complains)" gained the highest factor loading. According to Chen and Myagmarsuren, the customer is the final evaluator of the product and services quality and the identity of the brand relies merely on clear emphasize for the customers potential needs. ${ }^{19}$ Thus, providing feedback channels to identify customer's attitudes is crucial to promotion of a brand. ${ }^{20}$ According to Kim et al good relationships with the customer is key to improving brand value and enhanced loyalty of costumers to a hospital brand entails relationship-oriented marketing. ${ }^{21}$ Sirisha and Babu also emphasize the importance of patients' experience to hospital brand credit and recommend oral advertisement approach as a useful strategy in promote hospital brand. ${ }^{22}$

\section{Conclusions}

The present study conceptualized the requirements of successful hospital branding in 5 major dimensions including identity, image, competitiveness, strategy, and relationship. Identification of the major dimensions of hospital branding may help hospital administrators and health policy-makers to develop effective brand promotion strategies in hospital industry.

\section{Competing Interests}

The authors declare no competing interests.

\section{Authors' Contributions}

EA.was involved in the study design, gathering the data, analyzing the data, and drafting the manuscript. MHM and MRM revised the manuscript. AAN revised analyzing the data. All authors shave read and approved the final manuscript.

\section{Acknowledgements}

The authors are grateful to Dr. Etemadian, Dr. Barzegar , Dr. Soleimani and Dr. Shadpour for kindly sharing their viewpoints.

\section{References}

1. Khalili J. Modern Marketing Methods in New Era. Tehran: Roshd Press; 2011. [Persian].

2. Nafisi A. Relationship of branding and performance indicators in Mashhad Ghaem hospital. Health Management. 2011;41(13):15-20. [Persian].

3. Deragi P. The Sayings and Writings of the Marketing Teacher. Tehran: Rasa Publication; 2015. [Persian].

4. Whelan S, Davies G, Walsh M, Bourke R. Public Sector Corporate Branding and Customerorientation. J Bus Res. 2010;63:1164-1171.

5. Kimpakorn N, Tocquer G. Service brand equity and employee brand commitment. Journal of Services Marketing. 2010;24(5):387-388. doi:10.1108/08876041011060486 .

6. Zeinali $E$. The effect of brand dimensions on reusing the services [dissertation]. Tehran; 2012. [Persian].

7. Ekhlas M. The relationship between brand equity and image hospital [dissertation]. Tehran; 2014. [Persian].

8. RAK Free Trade Zone. Investment Opportunities in Ras Al Khaimah United Arab Emirates. Ras Al Khaimah United Arab Emirates; 2014.

9. Alberta Children's Hospital. Financial Statements of Alberta Children's Hospital Foundation. Published 2014.

10. Jarrahi M. Public Private Partnership. Presented in: Hospital Management Conference; 2011. [Persian].

11. Ahmadi Kamarposhti M. The effect of consumer satisfaction and brand identity on consumer loyalty within the personality trait [dissertation]. Tehran; 2012. [Persian].

12. Alserhan BA, Alserhan ZA. Naming Businesses: Names as Drivers of Brand Value. Int Bus J. 2012;22(4):329-342. doi:10.1108/10595421211247169.

13. Mirabi V, Akbariyeh $\mathrm{H}$, Tahmasebifard $\mathrm{H}$. A study of factors affecting on customers purchase intention.Journal of Multidisciplinary Engineering Science and Technology. 2015;2(1):267-273.

14. Ebrahimi Torki M. Brand valuation models. Marketing Articles Bank; 2012. http://MarketingArticles.ir. Accessed Aprril 3, 2015. [Persian]

15. Ziqi T. All-round marketing increases hospital popularity. Cell Biochem Biophys. 2015;72(2):367-370. doi:10.1007/ s12013-014-0468-5.

16. Yasin NM, Noor NN, Mohammad O. Does image of country-of-origin matter to brand equity? Journal of 
Product \& Brand Management. 2012;16(1):38-48. doi:10.1108/10610420710731142.

17. Keller KL, Parameswaran MG, Jacob I. Strategic brand management: building, measuring, and managing brand equity. India: Pearson Education; 2011.

18. Keller KL, Lehmann DR. Brands and branding: research findings and future priorities. Marketing Science. 2006;25(6):740-759.

19. Chen C, Myagmarsuren O. Brand equity, relationship quality, relationship value, and customer loyalty: evidence from the telecommunications services. Total Quality Management and Business Excellence. 2012;22(9):957974. doi:10.1080/14783363.2011.593872.

20. Barzegar M, Afzal E, Tabibi SJ, Delgoshaei B.
Relationship between leadership behavior, quality of work life and human resources productivity: data from Iran. Int J Hosp Res. 2013;1(1):1-14.

21. Kim KH, Kim KS, Kim DY, Kim JH, Kang SH. Brand equity in hospital marketing. J Bus Res. 2008;61(1):75-82.

22. Sirisha B, Babu MK. Branding of hospitals - through tangible factors by selected hospitals. International Journal of Multidisciplinary Management Studies. 2014;4(3):227-237.

\section{Please cite this article as:}

Afzal E, Modarresi MH, Maleki MR, Nasiripour AA. Designing a branding model for public teaching hospitals in Iran. Int $\mathrm{J}$ Hosp Res. 2016;5(2):74-82. doi:10.15171/ijhr.2016.14. 